\title{
Verticipyrone, a New NADH-fumarate Reductase Inhibitor, Produced by Verticillium sp. FKI-1083
}

\author{
Hideaki Ui, Kazuro Shiomi, Hideaki Suzuki, Hiroko Hatano, Hiromi Morimoto, \\ Yuichi Yamaguchi, Rokuro Masuma, Toshiaki Sunazuka, Hiroyuki Shimamura, \\ Kimitoshi Sakamoto, Kiyoshi Kita, Hideto Miyoshi, Hiroshi Tomoda, Satoshi Ōmura
}

Received: October 5, 2006 / Accepted: November 16, 2006

(C) Japan Antibiotics Research Association

\begin{abstract}
A new NADH-fumarate reductase inhibitor, verticipyrone, was isolated from the cultured broth of a fungus, Verticillium sp. FKI-1083. The structure was established as (E)-2-methoxy-3,5-dimethyl-6-(3-methyl-2undecenyl)-4H-pyran-4-one. Verticipyrone exhibited an $\mathrm{IC}_{50}$ value of $0.88 \mathrm{nM}$ against NADH-fumarate reductase of Ascaris suum. Verticipyrone inhibited both Ascaris and bovine heart complex I, and its synthetic analogue, 8,9dihydro-8-hydroxyverticipyrone, showed good selectivity against Ascaris complex I.
\end{abstract}

Keywords verticipyrone, electron transport enzyme inhibitor, NADH-fumarate reductase

\section{Introduction}

Several electron transport inhibitors are in common practical use. A complex II inhibitor, siccanin, produced by Helminthosporium siccans, is used clinically for dermatophytosis, and analogues of a complex III inhibitor, strobilurin A, produced by Strobilurus tenacellus, are used for phytopathogenic fungi. In the course of screening for anthelmintic antibiotics, we have been interested in the differences in energy metabolisms between the host and helminths [1]. The NADH-fumarate reductase (NFRD) system, which is found in many anaerobic organisms, is part of a special respiratory system in parasitic helminths [2]. The system is composed of complex I (NADH-rhodoquinone oxidoreductase) and complex II (rhodoquinol-fumarate oxidoreductase). Electrons from NADH are accepted by rhodoquinone through complex I, and then transferred to fumarate through complex II. Though this anaerobic electron transport system is inefficient, it can provide ATP in the absence of oxygen. During our screening for inhibitors of NFRD using Ascaris suum (roundworm) mitochondria, we obtained nafuredin, atpenins, and paecilaminol from cultured broth of fungi. Nafuredin is a selective inhibitor of helminth complex I which showed anthelmintic activity in vivo [3, 4]. Atpenins are the most potent complex II inhibitors, useful as tools for biochemical studies, though the inhibition is non-selective between helminths and mammals [5]. Paecilaminol is the first amino alcohol that has NFRD inhibitory activity [6].

Further screening for NFRD inhibitors led to the
K. Shiomi (Corresponding author), S. Ōmura (Corresponding author), H. Ui, R. Masuma, T. Sunazuka: Kitasato Institute for Life Sciences and Graduate School of Infectious Control Sciences, Kitasato University, Minato-ku, Tokyo 108-8641, Japan, E-mail: shiomi@lisci.kitasato-u.ac.jp and omura-s@kitasato.or.jp H. Shimamura: Graduate School of Infectious Control Sciences, Kitasato University, Minato-ku, Tokyo 108-8641, Japan H. Morimoto, H. Tomoda: School of Pharmaceutical Sciences, Kitasato University, Minato-ku, Tokyo 108-8641, Japan
K. Shiomi, H. Suzuki, H. Hatano, Y. Yamaguchi, T. Sunazuka, S. Ōmura: The Kitasato Institute, Minato-ku, Tokyo 108-8642, Japan

K. Sakamoto, K. Kita: Department of Biomedical Chemistry, Graduate School of Medicine, The University of Tokyo, Hongo, Bunkyo-ku, Tokyo 113-0033, Japan

H. Miyoshi: Division of Applied Life Sciences, Graduate School of Agriculture, Kyoto University, Kitashirakawa Oiwake-cho, Sakyo-ku, Kyoto 606-8502, Japan 
<smiles>CCCCCCCC/C(C)=C/Cc1oc(OC)c(C)c(=O)c1C</smiles>

Verticipyrone (1)<smiles>CC=C(C)C(O)C(C)C=C(C)C=CCC(C)=CCc1oc(OC)c(C)c(=O)c1C</smiles>

Actinopyrone A (3)<smiles>COc1oc([C@H]2C/C(=C/C(C)=C/C(C)=C/C(C)=C/c3ccc([N+](=O)[O-])cc3)CO2)c(C)c(=O)c1C</smiles>
Neoaureothin (spectinabilin, 5)<smiles>CCCCCCCCCCCc1oc(OC)c(C)c(=O)c1C</smiles>

Podopyrone (7)<smiles>CCCCCCCC[C@H](C)[C@H](O)Cc1oc(OC)c(C)c(=O)c1C</smiles>

8,9-Dihydro-8-hydroxyverticipyrone (2)<smiles>COc1oc([C@H]2C/C(=C/C(C)=C/c3ccc([N+](=O)[O-])cc3)CO2)c(C)c(=O)c1C</smiles>

Aureothin (4)<smiles>CCC(O)/C=C(C)/C=C/C/C(C)=C/Cc1oc(OC)c(C)c(=O)c1C</smiles>

Kalkipyrone (6)<smiles>CCC(=O)CCCCCCCCc1oc(OC)c(C)c(=O)c1C</smiles>

Fig. 1 Structures of verticipyrone (1) and related $\gamma$-pyrones $(\mathbf{2} \sim \mathbf{8})$.

isolation of a new compound, verticipyrone (1, Fig. 1), produced by a cultured broth of Verticillium sp. FKI-1083 [7]. The structure of 1 contains 2-methoxy-3,5-dimethyl- $\gamma$ pyrone similar to that of actinopyrone A (3) [8,9], aureothin (4) $[10 \sim 12]$, neoaureothin (spectinabilin, 5) [13 15], kalkipyrone (6) [16], and podopyrones $(7,8)$ [17 19]. In this report, we describe the taxonomy of the producing strain and the fermentation, isolation, structure elucidation, and biological properties of 1. Selective inhibition of $A$. suum complex I by a synthetic analogue, 8,9-dihydro-8-hydroxyverticipyrone, (2) is also shown.

\section{Results and Discussion}

\section{Taxonomy and Producing Strain FKI-1083}

Strain FKI-1083 (Fig. 2) was isolated from a soil sample collected on Yakushima Island, Kagoshima Prefecture, Japan. The strain was taxonomically determined as genus Verticillium sp. The strain has been deposited at International Patent Organism Depository, the National
Institute of Advanced Industrial Science and Technology, Tsukuba, Japan, as FERM BP-7804.

\section{Fermentation and Isolation of Verticipyrone}

A stock culture of the strain FKI-1083 was inoculated into a 500-ml Erlenmeyer flask containing $100 \mathrm{ml}$ of a seed medium. After incubation on a rotary shaker $(200 \mathrm{rpm})$ at $27^{\circ} \mathrm{C}$ for 3 days, one milliliter of the seed culture was transferred into each of twenty 500-ml Erlenmeyer flasks containing $100 \mathrm{ml}$ of a production medium. The fermentation was carried out on a rotary shaker $(200 \mathrm{rpm})$ at $27^{\circ} \mathrm{C}$ for 7 days.

Mycelia were collected from the cultured broth (2 liters) by centrifugation. The pellet was treated with methanol, and the extracted methanol solution was evaporated in vacuo to remove methanol. The aqueous extract was partitioned with ethyl acetate, and the organic layer was concentrated to dryness in vacuo to afford a crude material $(1.21 \mathrm{~g})$. This was applied on a silica gel column (Merck Art. 7734) and washed with $n$-hexane - ethyl acetate $(3: 1)$. Active fractions eluted with $n$-hexane - ethyl acetate $(1: 1)$ 


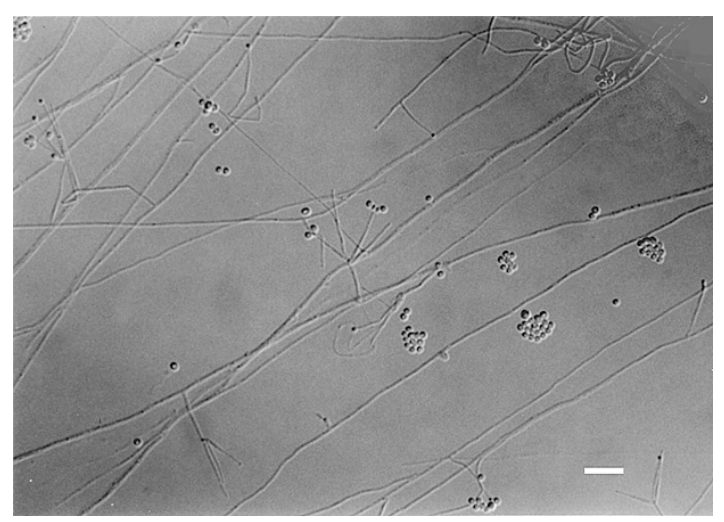

Fig. 2 Photomicrograph of phialide and conidia of Verticillium sp. FKI-1083. Bar represents $20 \mu \mathrm{m}$.

were concentrated to yield a crude material $(81.0 \mathrm{mg})$, which was then chromatographed over another silica gel column. The column was packed with $n$-hexane-ethyl acetate $(2: 1)$ and active fractions were eluted with $n$-hexane-ethyl acetate $(2: 1)$. The elution afforded a colorless oil of $1(61.1 \mathrm{mg})$

\section{Structure Elucidation of Verticipyrone}

Physico-chemical properties of $\mathbf{1}$ are summarized in Table 1. The molecular formula of $\mathbf{1}$ was established as $\mathrm{C}_{20} \mathrm{H}_{32} \mathrm{O}_{3}$ by HR-FAB-MS.

Chemical shifts of $\mathbf{1}$ in the ${ }^{1} \mathrm{H}$ and ${ }^{13} \mathrm{C}$ NMR are shown in Table 2. Analysis of the ${ }^{1} \mathrm{H}$ NMR, ${ }^{13} \mathrm{C}$ NMR, DEPT, and HMQC spectra revealed the presence of six quaternary, one methine, eight methylene, and five methyl carbons. A $\gamma$-pyrone ring was established on the basis of $\mathrm{HMBC}$ data (Fig. 3). A methoxy group 2- $\mathrm{OCH}_{3}\left(\delta_{\mathrm{H}} 4.00\right)$ showed correlation to a polarized olefinic carbon $\mathrm{C}-2(\delta$ 164.5), and the $\mathrm{C}-2$ correlated with a vinyl methyl $3-\mathrm{CH}_{3}$ $\left(\delta_{\mathrm{H}} 1.80\right)$. The $3-\mathrm{CH}_{3}$ had further correlations to another polarized olefinic carbon $\mathrm{C}-3(\delta$ 100.1) and a conjugated carbonyl C-4 $(\delta$ 183.1). The C-4 carbonyl showed correlation to a vinyl methyl 5- $\mathrm{CH}_{3}\left(\delta_{\mathrm{H}} 1.94\right)$, and the 5$\mathrm{CH}_{3}$ correlated with the second set of polarized olefinic carbons, C-5 ( $\delta$ 118.7) and C-6 ( $\delta$ 160.1). Therefore, a 2methoxy-3,5-dimethyl- $\gamma$-pyrone ring was suggested, and $\mathrm{UV}$ absorption at $250 \mathrm{~nm}$ and IR absorption at $1670 \mathrm{~cm}^{-1}$ $(\mathrm{C}=\mathrm{O})$ are consistent with the previous data for related compounds [9, 11, 14 19]

The structure of 3-methyl-2-undecenyl side chain (C7 C-17) attached to C-6 was deduced by ${ }^{1} \mathrm{H}-{ }^{1} \mathrm{H}$ COSY and $\mathrm{HMBC}$ as shown in Fig. 3. The geometrical isomerism of the olefin was elucidated as $E$ by the chemical shift of 9$\mathrm{CH}_{3}\left(\delta_{\mathrm{C}} 16.3\right)$ [20]. Correlations between $\mathrm{H}_{2}-16\left(\begin{array}{l}\delta \\ 1.28\end{array}\right)$ and $\mathrm{H}_{3}-17(\delta 0.88)$ in ${ }^{1} \mathrm{H}^{1} \mathrm{H}$ COSY and HMBC among 15 ,
Table 1 Physico-chemical properties of 1

\begin{tabular}{ll}
\hline $\begin{array}{l}\text { Appearance } \\
\text { Molecular formula }\end{array}$ & $\begin{array}{l}\text { Colorless oil } \\
\mathrm{C}_{20} \mathrm{H}_{32} \mathrm{O}_{3}\end{array}$ \\
$\begin{array}{l}\text { Molecular weight } \\
\text { HR-FAB-MS }(\mathrm{m} / \mathrm{z})\end{array}$ & 320.47 \\
$\quad$ found & $343.2247(\mathrm{M}+\mathrm{Na})^{+}$ \\
$\quad$ calcd & 343.2249 for $\mathrm{C}_{20} \mathrm{H}_{32} \mathrm{O}_{3} \mathrm{Na}$ \\
UV $\lambda_{\text {max }}{ }^{\mathrm{MeOH}} \mathrm{nm}(\varepsilon)$ & $204(20,500), 215(\mathrm{sh}, 13,720)$, \\
IR $v_{\text {max }}(\mathrm{KBr}) \mathrm{cm}^{-1}$ & $250(10,460)$ \\
& $2927,2854,1732,1670,1605,1464$, \\
Solubility & $1408,1379,1325,1250,1165$ \\
$\quad$ Soluble & \\
$\quad$ Insoluble & $\mathrm{CHCl}_{3}, \mathrm{EtOAc}, \mathrm{MeOH}$ \\
Color reaction & $\mathrm{H}_{2} \mathrm{O}, n$-hexane \\
$\quad$ Positive & $\mathrm{H}_{2} \mathrm{SO}_{4}, \mathrm{I}_{2}$ \\
\hline
\end{tabular}

Table $2{ }^{1} \mathrm{H}$ and ${ }^{13} \mathrm{C}$ data of $\mathbf{1}^{\mathrm{a}}$

\begin{tabular}{ccl}
\hline Position & $\delta_{\mathrm{C}}$ (mult) & $\delta_{\mathrm{H}}($ int, $J(\mathrm{~Hz}))$ \\
\hline 2 & $164.5 \mathrm{~s}$ & \\
3 & $100.1 \mathrm{~s}$ & \\
4 & $183.1 \mathrm{~s}$ & \\
5 & $118.7 \mathrm{~s}$ & \\
6 & $160.1 \mathrm{~s}$ & $3.40 \mathrm{~d}(2 \mathrm{H}, 7.2)$ \\
7 & $30.8 \mathrm{t}$ & $5.26 \mathrm{t}(1 \mathrm{H}, 7.2)$ \\
8 & $118.2 \mathrm{~d}$ & \\
9 & $140.7 \mathrm{~s}$ & $2.06 \mathrm{t}(2 \mathrm{H}, 7.6)$ \\
10 & $40.5 \mathrm{t}$ & $1.43 \mathrm{~m}(2 \mathrm{H})$ \\
11 & $28.8 \mathrm{t}$ & \\
12 & $30.5 \mathrm{t}$ & $1.26 \mathrm{~m}(8 \mathrm{H})$ \\
13 & $30.4 \mathrm{t}$ & \\
14 & $30.2 \mathrm{t}$ & $1.28 \mathrm{~m}(2 \mathrm{H})$ \\
15 & $33.0 \mathrm{t}$ & $0.88 \mathrm{t}(3 \mathrm{H} 7.2)$ \\
16 & $23.7 \mathrm{t}$ & $4.00 \mathrm{~s}(3 \mathrm{H})$ \\
17 & $14.4 \mathrm{q}$ & $1.80 \mathrm{~s}(3 \mathrm{H})$ \\
$2-\mathrm{OCH}_{3}$ & $56.4 \mathrm{q}$ & $1.94 \mathrm{~s}(3 \mathrm{H})$ \\
$3-\mathrm{CH}_{3}$ & $7.0 \mathrm{q}$ & $1.76 \mathrm{~s}(3 \mathrm{H})$ \\
$5-\mathrm{CH}_{3}$ & $10.0 \mathrm{q}$ & \\
$9-\mathrm{CH}_{3}$ & $16.3 \mathrm{q}$ & \\
\hline & &
\end{tabular}

${ }^{a}$ NMR spectra were recorded on a Varian Inova 600 spectrometer. Chemical shifts are shown in $\delta$ value (ppm) relative to $\mathrm{CD}_{3} \mathrm{OD}$ at $3.30 \mathrm{ppm}$ for ${ }^{1} \mathrm{H}$ NMR and at $49.8 \mathrm{ppm}$ for ${ }^{13} \mathrm{C} \mathrm{NMR}$.

16 , and 17 positions suggested the terminal linear structure of the hydrocarbon chain. Though the remaining two methylenes could not be assigned because protons from $\mathrm{H}_{2}-12$ to $\mathrm{H}_{2}-15$ showed almost the same chemical shifts, they should be included into the hydrocarbon chain. Thus, 
the structure of 1 was elucidated as (E)-2-methoxy-3,5dimethyl-6-(3-methyl-2-undecenyl)-4H-pyran-4-one (Fig. 1).

\section{Biological Activities of Verticipyrone}

We evaluated inhibitory activities of $\mathbf{1}$ against each complex using submitochondrial particles of $A$. suum and bovine heart (Table 3). Compound 1 inhibited NFRD from A. suum with an $\mathrm{IC}_{50}$ value of $0.88 \mathrm{nM}$ and the inhibition was specific to NADH-rhodoquinone oxidoreductase (complex I). It also inhibited NADH-ubiquinone oxidoreductase (complex I) from bovine heart to the same extent as $A$. suum enzymes. However, the $\mathrm{IC}_{50}$ values differed greatly between NFRD and NADH-rhodoquinone oxidoreductase of A. suum and between NADH oxidase and NADHubiquinone oxidoreductase of bovine heart. This may be due to the difference of quinone concentration. Endogenous quinones were used for NFRD and NADH oxidase assays, while rhodoquinone and ubiquinone were added exogenously for NADH-quinone oxidoreductase assays. Therefore, the latter assays contained higher concentration of quinones, and competitive (or partially competitive) inhibitors may have reduced their inhibition.

We have accomplished the total synthesis of $\mathbf{1}$ and prepared some analogues of $\mathbf{1}$ [21]. Among them, 8,9-dihydro-8-hydroxyverticipyrone (2) showed potent inhibition against Ascaris complex $\mathrm{I}\left(\mathrm{IC}_{50}=2.0 \mathrm{nM}\right)$.

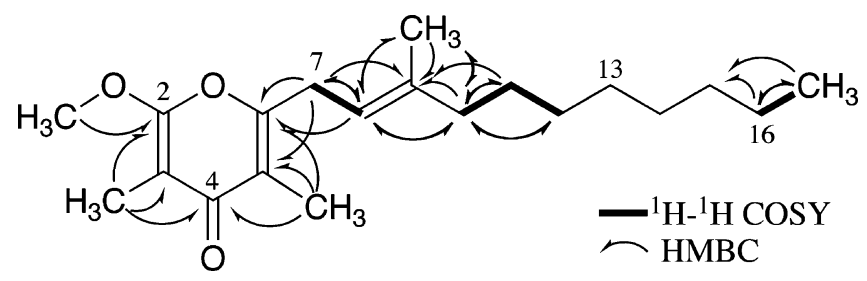

Fig. 3 Selected ${ }^{1} \mathrm{H}-{ }^{1} \mathrm{H}$ COSY and $\mathrm{HMBC}$ correlations of $\mathbf{1}$.
The inhibition of $\mathbf{2}$ against bovine heart complex I was 100 times less potent, and 2 exhibited good selectivity to Ascaris complex I. The similarity of the $\mathrm{IC}_{50}$ values between NFRD and NADH-rhodoquinone oxidoreductase of $A$. suum suggested that $\mathbf{2}$ may not competitive to rhodoquinone at Ascaris complex I inhibition. Further studies are required to clarify the inhibitory mechanisms of these compounds.

Compound $\mathbf{1}$ is produced by a fungus and has 6substituted-2-methoxy-3,5-dimethyl-4H-pyran-4-one. Such compounds are found from not only fungi but also cyanobacteria, actinomycetes, and plants. Among them, aureothin (4) was reported to have a complex I inhibitory activity [12]. We found that neoaureothin (5) inhibited NFRD at $\mathrm{IC}_{50}$ value of $15 \mathrm{nM}$. A $\gamma$-pyrone with a side chain seems to be essential to inhibit complex I, but interestingly, 4 is not competitive to the structurally-related substrate, quinone [12].

Nematocidal and insecticidal activities of $\mathbf{1}$ were studied by a microplate assay using the free-living nematode Caenorhabditis elegans and brine shrimp Artemia salina. Minimum growth inhibitory concentrations of $\mathbf{1}$ against C. elegans and A. salina were $20 \mu \mathrm{g} / \mathrm{ml}$ and $2.0 \mu \mathrm{g} / \mathrm{ml}$, respectively. Kalkipyrone (6) was reported to show similar toxicity against brine shrimp $\left(\mathrm{LD}_{50}=1 \mu \mathrm{g} / \mathrm{ml}\right)$ [16]. As shown in Table 4, 1 exhibited moderate antimicrobial activity against Gram-positive bacteria. Actinopyrone A (3) exhibited weak antimicrobial activities against some Gram-positive bacteria and dermatophytes, in addition to coronary vasodilating activities in anaesthetized dogs [9].

\section{Experimental}

\section{General}

NMR spectra were recorded on a Varian Inova 600

Table 3 Inhibition of NFRD and NADH oxidase by $\mathbf{1}$ and $\mathbf{2}$

\begin{tabular}{|c|c|c|c|c|}
\hline \multirow{2}{*}{ Origin } & \multirow{2}{*}{ Enzyme } & \multirow{2}{*}{ Complex } & \multicolumn{2}{|c|}{$I_{50}[\mathrm{nM}]$} \\
\hline & & & 1 & 2 \\
\hline \multirow[t]{3}{*}{ A. suum } & $\mathrm{NADH}$-fumarate reductase & $1+11$ & 0.88 & 1.5 \\
\hline & NADH-rhodoquinone oxidoreductase & । & 49 & 2.0 \\
\hline & Rhodoquinol-fumarate oxidoreductase & $\|$ & $>100,000$ & $>100,000$ \\
\hline \multirow[t]{4}{*}{ Bovine heart } & NADH oxidase & $I+I I I+I V$ & 1.3 & 20 \\
\hline & NADH-ubiquinone oxidoreductase & I & 46 & 200 \\
\hline & Succinate-ubiquinone oxidoreductase & $\|$ & $>100,000$ & $>100,000$ \\
\hline & Ubiquinol-cytochrome c oxidoreductase & III & 26,000 & 80,000 \\
\hline
\end{tabular}


Table 4 Antimicrobial activity of $\mathbf{1}$

\begin{tabular}{lc}
\hline \multicolumn{1}{c}{ Microorganisms } & MIC $(\mu \mathrm{g} / \mathrm{ml})$ \\
\hline Staphylococcus aureus ATCC6538P & 6.25 \\
Bacillus subtilis ATCC6633 & 6.25 \\
Micrococcus luteus ATCC9341 & 6.25 \\
Mycobacterium smegmatis ATCC607 & 12.5 \\
Escherichia coli NIHJ & $>100$ \\
Escherichia coli IFO12734 & $>100$ \\
Pseudomonas aeruginosa IFO3080 & $>100$ \\
Xanthomonas campestris pv. oryzae KB88 & $>100$ \\
Candida albicans KF1 & $>100$ \\
Saccharomyces cerevisiae KF26 & $>100$ \\
Aspergillus niger ATCC6275 & 100 \\
Mucor racemosus IFO4581 & 100 \\
Acholeplasma laidlawii PG8 KB174 & $>50$ \\
Bacteroides fragilis ATCC23745 & $>50$ \\
\hline
\end{tabular}

spectrometer $\left({ }^{2-3} J_{\mathrm{CH}}=8 \mathrm{~Hz}\right.$ in $\left.\mathrm{HMBC}\right)$. Chemical shifts are shown in $\delta$ values (ppm) relative to $\mathrm{CD}_{3} \mathrm{OD}$ at $3.30 \mathrm{ppm}$ for ${ }^{1} \mathrm{H}$ NMR and at $49.8 \mathrm{ppm}$ for ${ }^{13} \mathrm{C}$ NMR. Mass spectrometry was conducted on a JEOL JMS-AX505 HA spectrometer. The UV and IR spectra were measured with Shimadzu UV-240 spectrophotometer and Horiba FT-210 Fourier transform infrared spectrometer, respectively.

\section{Taxonomic Studies of the Producing Organism}

Morphological observations of the verticipyrone-producing strain were carried out using an Olympus Vanox-S AH-2 microscope.

\section{Media}

The seed medium consisted of glucose $2.0 \%$, Polypepton (Nihon Pharmaceutical Co.) $0.5 \%$, yeast extract (Oriental Yeast Co.) $0.2 \%, \mathrm{KH}_{2} \mathrm{PO}_{4} 0.1 \%, \mathrm{MgSO}_{4} \cdot 7 \mathrm{H}_{2} \mathrm{O} 0.05 \%$, and agar $0.1 \%, \mathrm{pH} 5.7$. The production medium consisted of potato dextrose broth (Difco) 2.4\%, malt extract (Difco) $1.5 \%, \mathrm{MgPO}_{4} \cdot 8 \mathrm{H}_{2} \mathrm{O} 0.5 \%$, and agar $0.1 \%$, pH 6.0 .

\section{Biological Studies}

Submitochondrial particles were prepared from adult $A$. suum and bovine heart and used for electron transport enzyme assays. The enzyme assays were performed as described previously [3]. The assay method for nematocidal and insecticidal activities was reported previously [22]. The antimicrobial activity was measured by agar dilution method.

Acknowledgements We are grateful to Dr. Achim Harder of Bayer HealthCare AG, Animal Health-Research \& Development-
Parasiticides for valuable discussions. We also thank Ms. Akiko Nakagawa and Ms. Chikako Sakabe of the School of Pharmaceutical Sciences, Kitasato University for measurements of mass spectra. This work was supported by a Grant-in-Aid for Scientific Research (14593006 to K.S. and 17790274 and $18 \mathrm{GS} 0314$ to K.K.) and a Grant-in-Aid for Encouragement of Young Scientists (12771373 to H.U.). This work was also supported in part by Grant of the 21st Century COE Program, Ministry of Education, Culture, Sports, Science, and Technology.

\section{References}

1. Komuniecki R, Tielens AGM. Carbohydrate and energy metabolism in parasitic helminths. In Molecular Medical Parasitology. Ed., J. J. Marr, et al., pp. 339-358, Academic Press, London (2003)

2. Kita K, Nihei C, Tomitsuka E. Parasite mitochondria as drug target: diversity and dynamic changes during the life cycle. Curr Med Chem 10: 2535-2548 (2003)

3. Ōmura S, Miyadera H, Ui H, Shiomi K, Yamaguchi Y, Masuma R, Nagamitsu T, Takano D, Sunazuka T, Harder A, Kölbl H, Namikoshi M, Miyoshi H, Sakamoto K, Kita K. An anthelmintic compound, nafuredin, shows selective inhibition of complex I in helminth mitochondria. Proc Natl Acad Sci USA 98: 60-62 (2001)

4. Ui H, Shiomi K, Yamaguchi Y, Masuma R, Nagamitsu T, Takano D, Sunazuka T, Namikoshi M, Ōmura S. Nafuredin, a novel inhibitor of NADH-fumarate reductase, produced by Aspergillus niger FT-0554. J Antibiot 54: 234-238 (2001)

5. Miyadera H, Shiomi K, Ui H, Yamaguchi Y, Masuma R, Tomoda H, Miyoshi H, Osanai A, Kita K, Ōmura S. Atpenins, potent and specific inhibitors of mitochondrial complex II (succinate-ubiquinone oxidoreductase). Proc Natl Acad Sci USA 100: 473-477 (2003)

6. Ui H, Shiomi K, Suzuki H, Hatano H, Morimoto H, Yamaguchi Y, Masuma R, Sakamoto K, Kita K, Miyoshi H, Tomoda H, Tanaka H, Ōmura S. Paecilaminol, a new NADH-fumarate reductase inhibitor, produced by Paecilomyces sp. FKI-0550. J Antibiot 59: 591-596 (2006)

7. Ōmura S, Shiomi K, Masuma R. Novel substance FKI-1083 and process for producing the same. PCT Int Appl, WO/2003/050104, June 19 (2003)

8. Yano K, Yokoi K, Sato J, Oono J, Kouda T, Ogawa Y, Nakashima T. Actinopyrones A, B and C, new physiologically active substances. I. Producing organism, fermentation, isolation and biological properties. J Antibiot 39: 32-37 (1986)

9. Yano K, Yokoi K, Sato J, Oono J, Kouda T, Ogawa Y, Nakashima T. Actinopyrones A, B and C, new physiologically active substances. II. Physico-chemical properties and chemical structures. J Antibiot 39: 38-43 (1986)

10. Maeda K. Chemical studies on antibiotic substances, IV. A crystalline toxic substance of Streptomyces thioluteus 
producing aureothricin. J Antibiot A 6: 137-138 (1953)

11. Hirata Y, Nakata H, Yamada K, Okuhara K, Naito T. The structure of aureothin, a nitro compound obtained from Streptomyces thioluteus. Tetrahedron 14: 252-274 (1961)

12. Friedrich T, Van Heek P, Leif H, Ohnishi T, Forche E, Kunze B, Jansen R, Trowitzsch-Kienast W, Höfle G, Reichenbach $\mathrm{H}$, Weiss $\mathrm{H}$. Two binding sites of inhibitors in NADH: ubiquinone oxidoreductase (complex I). Relationship of one site with the ubiquinone-binding site of bacterial glucose: ubiquinone oxidoreductase. Eur J Biochem 219: 691-698 (1994)

13. Cassinelli G, Grein A, Orezzi P, Pennella P, Sanfilippo A. New antibiotics produced by Streptoverticillium orinoci, n. sp. Arch Mikrobiol 55: 358-368 (1967)

14. Cardani C, Ghiringhelli D, Selva A, Arcamone F, Camerino B, Cassinelli G. The structure of neoaureothin. Chim Ind 52: 793-794 (1970)

15. Kakinuma K, Hanson CA, Rinehart KL Jr. Spectinabilin, a new nitro-containing metabolite isolated from Streptomyces spectinabilis. Tetrahedron 32: 217-222 (1976)

16. Graber MA, Gerwick WH. Kalkipyrone, a toxic $\gamma$-pyrone from an assemblage of the marine cyanobacteria Lyngbya majuscula and Tolypothrix sp. J Nat Prod 61: 677-680 (1998)

17. Zdero C, Bohlmann F, King RM, Robinson H. Pyrone derivatives from Podolepis hieracioides and sesquiterpene acids from Cassinia longifolia. Phytochemistry 26: 187-190 (1987)

18. Jaensch M, Jakupovic J, King RM, Robinson H. Pyrones and other constituents from Podolepis species. Phytochemistry 28: 3497-3501 (1989)

19. Kanazawa T, Ohkawa Y, Kuda T, Minobe Y, Tani T, Nishizawa M. $\gamma$-Pyrones from Gonystylus keitheii, as new inhibitors of parathyroid hormone (PTH)-induced Ca release from neonatal mouse calvaria. Chem Pharm Bull 45: 1046-1051 (1997)

20. Barlow L, Pattenden G. Synthesis of poly-Z-isomers of 2,6,11,15-tetramethylhexadeca-2,6,8,10,14-pentaene, a $\mathrm{C}_{20}$ analogue of phytoene. Re-examination of the stereochemistry of a new isomer of phytoene from Rhodospirillum rubrum. J Chem Soc Perkin I 1976 : 1029-1034 (1976)

21. Shimamura H, Sunazuka T, Izuhara T, Hirose T, Shiomi K, Ömura S. Total synthesis of verticipyrone, and biological evaluation of its synthetic analogues. Org Lett (in press)

22. Enomoto Y, Shiomi K, Matsumoto A, Takahashi Y, Iwai Y, Harder A, Kölbl H, Woodruff HB, Ōmura S. Isolation of a new antibiotic oligomycin G produced by Streptomyces sp. WK-6150. J Antibiot 54: 308-313 (2001) 